\title{
Clinical evaluation of covered stents in the treatment of superficial femoral artery pseudoaneurysm in drug abusers
}

\author{
JIAN XU $^{1 *}$, ZHAO ZHENG $^{2 *}$, YONG YANG $^{1 *}$, WEI ZHANG ${ }^{1}$, HONGLIANG ZHAO $^{1}$, BEI E $^{1}$ and MINWEN ZHENG ${ }^{1}$ \\ Departments of ${ }^{1}$ Radiology and ${ }^{2}$ Burns and Cutaneous Surgery, Xijing Hospital, \\ Fourth Military Medical University, Xi'an, Shaanxi 710032, P.R. China
}

Received May 2, 2016; Accepted December 4, 2017

DOI: $10.3892 / \mathrm{mmr} .2018 .8431$

\begin{abstract}
The present study aimed to investigate the technical feasibility and initial clinical outcomes of a covered stent for the endovascular treatment of superficial femoral artery (SFA) pseudoaneurysm in drug abusers. A total of 29 drug abuse patients with SFA pseudoaneurysm, as confirmed by color Doppler sonography, were enrolled to the present study between January 2012 and May 2014. All patients were treated percutaneously by implantation of a covered stent. Physical examination and lower extremity computed tomography angiography were performed at 1 and 9 months postoperation. Furthermore, the ankle-brachial index (ABI) of all patients was measured. The results indicated that placement of the covered stent was technically successful in all 29 patients. All of the ruptured pseudoaneurysms were successfully sealed with no cases of intraprocedural mortality. In addition, all patients' conditions improved rapidly; active hemorrhage subsidence and vascular bruit disappearance were immediately detected following implantation of the covered stent. During the follow-up period, pain was markedly alleviated and pulsatile mass was decreased as time increased. No complaints or complications were documented. A total of 9 months postoperation, pain and pulsatile mass were not detected. The patency rate of the stent was $100 \%$, and no migration, occlusion or infection was detected. In addition, the ABI was significantly improved, from $0.52 \pm 0.09$ to $0.97 \pm 0.37$ $(\mathrm{P}<0.01)$. In conclusion, the placement of a covered stent may be considered a promising approach to provide an effective,
\end{abstract}

Correspondence to: Dr Minwen Zheng, Department of Radiology, Xijing Hospital, Fourth Military Medical University, 127 Changle West Road, Xi'an, Shaanxi 710032, P.R. China

E-mail: xjyyradiology@163.com

*Contributed equally

Abbreviations: ABI, ankle-brachial index; CTA, computed tomography angiography; FA, femoral artery; MDCT, multidetector computed tomographic; SFA, superficial femoral artery

Key words: pseudoaneurysm, covered stent, superficial femoral artery safe and minimally invasive option for the treatment of SFA pseudoaneurysm in drug abusers.

\section{Introduction}

Pseudoaneurysm refers to the focal enlargement of the vascular lumen due to partial or complete disruption of the arterial wall and a contained bleed $(1,2)$. Various etiological factors have been described with regards to the formation of pseudoaneurysms, including iatrogenic injury, trauma, infection, numerous punctures and local inflammation. As the number of drug abusers worldwide has increased (16-38 million) (3), so has the prevalence of trauma-induced pseudoaneurysm in drug abusers. FA pseudoaneurysm accounts for $\sim 0.14 \%$ of complications associated with the intravenous injection of drugs (4). A previous study estimated that the annual prevalence of mycotic pseudoaneurysm in intravenous drug abusers was $0.03 \%$ in San Francisco (5). Pseudoaneurysm in drug abusers is predominantly caused by repeated trauma to the arterial walls in response to intravenous puncture. In addition to painful and pulsatile swelling in the femoral region, drug abusers with pseudoaneurysm present with abscess, cellulitis and endocarditis. In general, small pseudoaneurysms $(<2 \mathrm{~cm})$ can be restored spontaneously, whereas large and complex pseudoaneurysms require appropriate treatment $(6,7)$. Pseudoaneurysms should be treated as soon as possible after diagnosis, due to the tendency of various complications, including rupture and compression of the adjacent femoral vein or the femoral nerve (8-11).

In the past, surgical treatment involving ligation, grafting or bypassing was considered the most reliable therapeutic option for the treatment of PA. In addition, several nonsurgical methods have been used as alternatives, including close observation, ultrasound-guided thrombin injection and compression. Recently, the use of endovascular stent-graft repair has garnered attention as a surgical reconstructive technique, particularly for drug abuse patients with bleeding pseudoaneurysm $(12,13)$. The first case of treating pseudoaneurysm with the implantation of a covered stent (Palmaz P294 stent; autogenous vein-covered and balloon-expanded) was reported by McGraw et al in 1998 (14), and numerous studies regarding the use of covered stents in the treatment of pseudoaneurysm have been conducted since $(1,15,16)$. These previous studies only contain information on one or two cases; however, they have indicated that percutaneous endovascular treatment using 
a covered stent may be a safe and feasible method for the treatment of pseudoaneurysm. The present study recruited 29 drug abuse patients with superficial FA (SFA) pseudoaneurysm from a single institution and percutaneously repaired the pseudoaneurysms using polyethylene terephthalate-covered stents, in order to further evaluate their clinical efficacy.

\section{Materials and methods}

Patients. The present study was approved by the Xijing Hospital Institutional Review Board (Xi'an, China) and informed written consent was obtained from each patient, following a discussion of treatment options, and of the endovascular operation with its risks and benefits.

Over 2 years, between January 2012 and May 2014, a total of 29 suspected pseudoaneurysm patients ( 21 men and 8 women; age range, $25-52$ years; mean age 40.38 years) with 5-10 years of intravenous drug abuse history were presented to the emergency department, due to the hemorrhage and rupture of their pseudoaneurysms. Following simple application of a compression bandage, they were admitted to the angiographic suite of the Xijing Hospital (Xi'an, China).

All patients were noted to be undergoing an inflammatory flare-up and pigmentation was detected in the inguinal region following numerous punctures. The patients exhibited pain at the puncture site, due to repeated trauma of the arterial wall, and a progressively enlarged pulsatile mass was palpated in each case. A vascular bruit, or dual-phase (systolic and diastolic) vascular bruit, was noted in all patients. Preoperational physical examination also revealed that dorsalis pedis pulse was faint in 9 cases $(31.03 \%)$ and not palpable in 14 cases (48.28\%) with bimanual palpation. Active hemorrhage was noted in 21 cases (72.41\%). Furthermore, 3 cases (10.34\%) were positive for hepatitis B virus, 5 cases (17.24\%) were positive for hepatitis $\mathrm{C}$ virus, 2 cases $(6.70 \%)$ were positive for syphilis and 1 case $(3.45 \%)$ was positive for human immunodeficiency virus-3 (Table I).

Sonography. The diagnosis of a pseudoaneurysm was confirmed by color Doppler sonography (LOGIQ P5; GE Healthcare, Waukesha, WI, USA). The operator had $>10$ years of experience with sonography. The diagnosis was based on detecting an extravascular false lumen connected to the FA at the puncture site. Doppler sonography detected 2-way blood flow signals (pansystolic flow from the FA to the neck of the pseudoaneurysm, and pandiastolic reverse flow in the neck of the pseudoaneurysm) in all 29 patients (Fig. 1). These signals were located in the SFA. The pseudoaneurysm neck was first localized using a color Doppler technique, which exhibited abnormal color flow at the lesion site (2-way blood flow signals). The ultrasound system was then shifted to the gray scale mode without moving the probe. The widest part of the lesion was marked and measured.

CT protocol. To detect the morphology, origin and neck of the PA, multidetector computed tomographic (MDCT) angiography was performed. All patients were scanned on a dual-source MDCT scanner (SOMATOM Definition Flash; Siemens Healthcare, Erlangen, Germany) following administration of an iodinated contrast agent (70-100 ml Ultravist 370 ) at $3 \mathrm{ml} / \mathrm{sec}$. All patients were scanned from the level of the thoracic inlet to the level of the mid-thigh region using a nonelectrocardiographically gated helical mode of acquisition with the following parameters: Gantry rotation time, 330 msec; beam collimation, $24 \times 1.2 \mathrm{~mm}$; tube voltage, $120 \mathrm{kVp}$; reference tube current, 170 effective $\mathrm{mAs}$ with anatomic based tube current modulation; beam pitch, 0.6. Images were reconstructed with 3-mm slice thickness.

Procedure. The operations were performed by interventional radiologists in a dedicated endovascular suite with a fixed imaging unit. The patients were maintained under local anesthesia in a supine position. The contralateral FA was punctured using modified Seldinger's technique, and selective angiography was performed by insertion of a Cobra sheath into the common iliac artery or external iliac artery, in order to identify the location and size of the pseudoaneurysm. Furthermore, angiography was performed to check for the inflow vessels and significant outflow vessels, and the compression extent of adjacent structures was also evaluated. The suitable site was confirmed following FA angiography in multi-angle image. Under roadmap guidance, the sheath and guidewire were introduced into the distal SFA, and the guidewire was then exchanged with a 0.035 -inch stiff guidewire using an angiographic catheter. Finally, a 9 F introducer sheath (William Cook Europe, Bjæverskov, Denmark) was placed over the stiff guidewire. Following confirmation of pseudoaneurysm by the utilization of selective catheters and angiograms, a self-expandable stent graft (Fluency Plus Vascular Stent Graft; Bard GmbH, Karlsruhe, Germany) of a suitable diameter and length was passed over the stiff guidewire and deployed at the site with roadmap guidance, with attention not to cover the orifice of the SFA. In some patients, minimal extravasation from the upper and lower end of the stent segment was revealed by control angiograms. Subsequently, the stent was expanded by dilatation of a balloon catheter of the same diameter. Finally, the control angiogram detected no signs of pseudoaneurysm filling and the stent was patent; therefore, the sheath and the wire were removed.

As study medication, all patients received $70 \mathrm{IU} / \mathrm{kg}$ heparin during the procedure. Patients were discharged from the hospital 2 or 3 days after the operation and were administered $100 \mathrm{mg}$ aspirin and $75 \mathrm{mg}$ Clopidogrel Hydrogen Sulphate Tablets once a day for 1 month, in order to ensure stent patency.

The follow-up patient visits were scheduled at 1 and 9 months post-treatment, and included physical examination, computed tomography angiography (CTA) examination and assessment of the ankle-brachial index (ABI) (17).

Statistical analysis. The continuous variables of age and other baseline conditions were expressed as the mean \pm standard deviation. Other discrete variables were summarized as count and percentage. The results of ABI were compared using one-way analysis of variance followed by the Student-Newman-Keuls test. $\mathrm{P}<0.05$ was considered to indicate a statistically significant difference. All analyses were performed using SPSS software (v19.0; SPPS Inc., Chicago, IL, USA).

\section{Results}

Radiological findings. Suspected Enterobacter aerogenes infection with air in the peripheral soft tissue was detected in 
Table I. Demographic characteristics of the patients with superficial femoral artery pseudoaneurysm.

\begin{tabular}{lc}
\hline Characteristic $(\mathrm{n}=29)$ & $\mathrm{n}(\%)$ \\
\hline Age, year & $40.38 \pm 9.88$ \\
Male & $21(72.41)$ \\
BMI, kg/m ${ }^{2}$ & $25 \pm 8$ \\
Medical history & \\
Hypertension & $2(6.70)$ \\
Diabetes & $2(6.70)$ \\
Smoking & $19(65.52)$ \\
Physical examination & \\
Dorsalis pedis pulse & \\
Faint & $9(31.03)$ \\
Non-palpable & $14(48.28)$ \\
Active hemorrhage & $21(72.41)$ \\
Laboratory examination & \\
Hepatitis B virus, + & $3(10.34)$ \\
Hepatitis C virus, + & $5(17.24)$ \\
Syphilis, + & $2(6.70)$ \\
HIV3, + & $1(3.45)$ \\
\hline
\end{tabular}

Values are expressed as the mean \pm standard deviation or $\mathrm{n}(\%)$. BMI, body mass index; HIV3, human immunodeficiency virus-3.

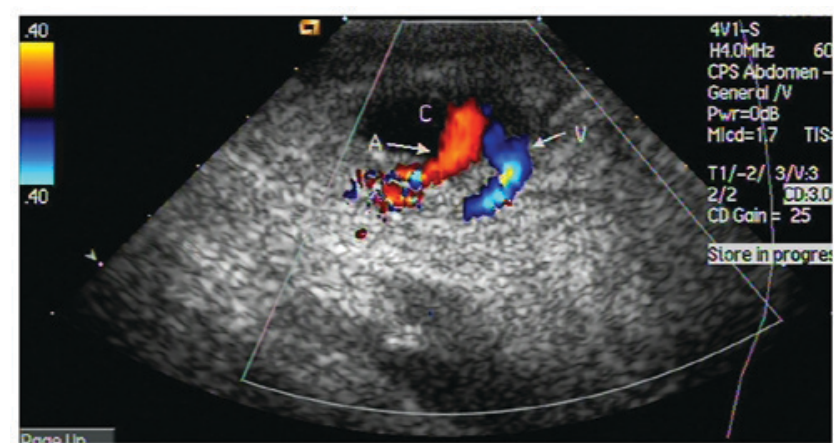

Figure 1. Color Doppler sonography prior to treatment. Shunt flow signals are seen in the pseudoaneurysm neck, which is connected to the artery by a tear. Turbulent-like flow is observed in the pseudoaneurysm body. A, artery; C, cavity; V, vein.

5 cases (17.24\%), extensive pseudoaneurysm cavity thrombosis was detected in 11 cases $(37.93 \%)$ and arteriovenous fistula was present in 1 case $(3.45 \%)$ (Table II). The mean length and width of the pseudoaneurysms were $8.4 \pm 3.5$ and $6.0 \pm 2.9 \mathrm{~cm}$, respectively, and the mean entry tear size was $5.7 \pm 2.4 \mathrm{~mm}$, as confirmed by sonography. Lower extremity CTA in the arterial and venous phases demonstrated the presence of a pseudoaneurysm of the upper SFA in all patients (Fig. 2). The pseudoaneurysm was spherical in shape. The corresponding FAs in 29 cases were constricted, due to large pseudoaneurysm compression.

Outcomes. Placement of the covered stents was technically successful in all 29 patients. When a corresponding stent
Table II. Preoperational diagnostic findings.

\begin{tabular}{lc}
\hline Radiological finding & $\mathrm{n}(\%)$ \\
\hline Air in peripheral soft tissue & $5(17.24)$ \\
Thrombus in pseudoaneurysm & $11(37.93)$ \\
Arteriovenous fistula & $1(3.45)$ \\
Pseudoaneurysm length $(\mathrm{cm})$ & $8.4 \pm 3.5$ \\
Pseudoaneurysm width $(\mathrm{cm})$ & $6.0 \pm 2.9$ \\
Entry tear size (mm) & $5.7 \pm 2.4$ \\
Stenosis of femoral artery caused by compression & $29(100)$
\end{tabular}

Values are expressed as the mean \pm standard deviation or $\mathrm{n}(\%)$.

Table III. Outcomes of endovascular treatment.

\begin{tabular}{lc}
\hline Outcome & $\mathrm{n}(\%)$ \\
\hline Technical success of stent deployment & $29(100)$ \\
Outcomes of intervention & \\
Normal dorsalis pedis pulse & $29(100.00)$ \\
Active hemorrhage & $0(0.00)$ \\
Vascular bruit & $0(0.00)$ \\
Additional treatment & $1(3.45)$ \\
Stent length (mm) & $43.75 \pm 14.08$ \\
Stent diameter (mm) & $7.25 \pm 1.39$ \\
Operation time (min) & $70 \pm 15$ \\
Duration of hospitalization (days) & $2 \pm 1.20$
\end{tabular}

Values are expressed as the mean + standard deviation or $\mathrm{n}(\%)$. ${ }^{a}$ Additional treatment: Urokinase thrombolysis via indwelling catheters for the therapy of stent thrombosis.

was deployed to cover the entry tear of the pseudoaneurysm, abnormal flow was restored immediately. All the ruptured pseudoaneurysms were successfully sealed, with no cases of intraprocedural mortality. Contrast medium extravasation into the lumen of the pseudoaneurysm was detected in 16 cases $(55.17 \%)$; however, the extravasation was controlled immediately by distending the balloon catheter. In addition, in 1 case, follow-up angiography was performed $24 \mathrm{~h}$ after stent placement, in order to check the patency of the FA due to soreness. As a result, stent thrombosis was detected in this case, and blood flow was successfully reestablished following thrombolytic therapy.

Furthermore, dorsalis pedis pulse was easily palpated at the completion of the operation. Signs of active hemorrhage subsided and the patients' condition improved rapidly; the vascular bruit immediately disappeared and pain in the majority of patients was obviously alleviated following placement of the covered stent (Table III).

Based on the preoperative CTA measurement and the arteriography confirmation of these findings, the chosen stent diameter varied between 6 and $10 \mathrm{~mm}$. The length of the stent ranged between 40 and $80 \mathrm{~mm}$ (Table III). The average 


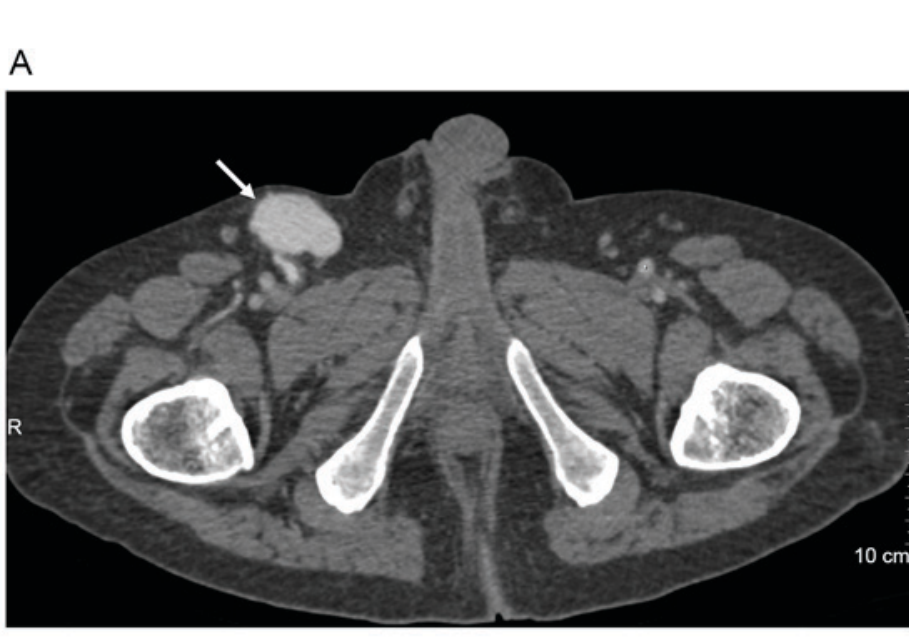

\section{B}

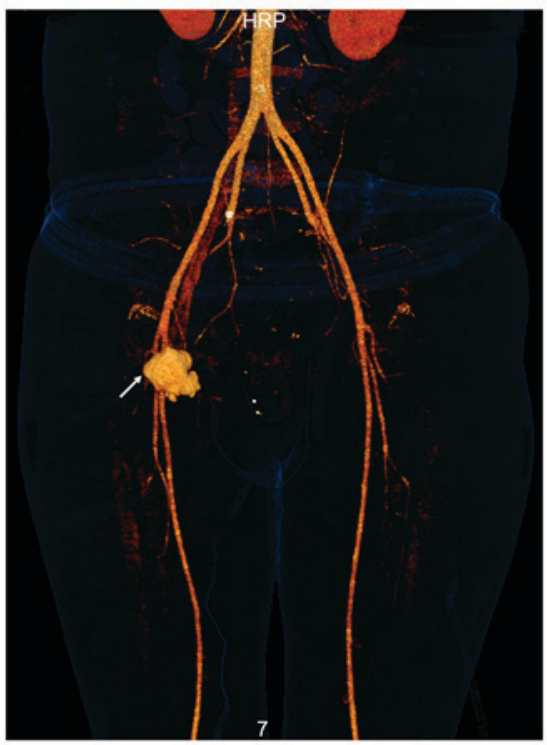

Figure 2. Radiological findings of one case prior to operation. (A) A multiplanar reconstructed image in axial view and (B) a volume-rendering image in anterior-posterior view. The morphology of the pseudoaneurysm and SFA are clearly presented on the images (white arrow).

operative time was 70 \pm 15 min (range, 45-90 min). Finally, all patients remained asymptomatic, apyrexial and hemodynamically stable postoperation, and the average hospitalization time was $2 \pm 1.20$ days.

Follow-up. A total of 8 patients had to be excluded from follow-up analysis due to major protocol violations: 5 patients continued to inject at the stent site and 3 patients withdrew their informed consent after discharge. The pulsatile mass in 29 cases and pain in 13 cases in the inguinal region did not immediately subside after treatment; however, these symptoms were alleviated over time. At 1-month postoperation, pulsatile mass was still noted in 18 cases $(62.07 \%)$ and pain was still noted in 5 cases (17.24\%). After 9 months, no pulsatile mass or pain was detected (Table IV). In addition, stent thrombosis was not detected. Furthermore, the patency rate of the stents was $100 \%$, with no stent migration, restenosis, fracture, occlusion or infections 9 months postoperation.

Clinical examinations and CTA performed at 1 and 9 months postoperation confirmed normal blood flow in the lower extremity, which reflected the patency of the stent, and no blood flow in the pseudoaneurysm was detected. Furthermore, no complaint or complication was reported during follow-up (Figs. 3 and 4).

The ABI in these subjects increased from $0.52 \pm 0.09$ immediately post-operation to $0.92 \pm 0.05$ prior to discharge $(\mathrm{P}<0.01)$. At 1 month follow-up the ABI was $0.96 \pm 0.27$ and after 9 months it was $0.97 \pm 0.37$. ABI values at discharge, and 1 and 9 months postoperation were all significantly increased compared with ABI post-operation; however, there was no significant difference between these three time points (Table IV).

\section{Discussion}

The results of the present study validated that endovascular repair using a covered stent may be considered a promising therapeutic option for the treatment of SFA pseudoaneurysm in drug abusers. In the present study, 29 drug abuse patients with SFA pseudoaneurysms were successfully treated with covered stents. In addition, the follow-up data indicated promising short-term outcomes.

FA pseudoaneurysm represents a common complication following FA overuse in diagnostic, therapeutic and parenteral drug use applications (18-20). Pseudoaneurysm rupture in drug abusers is a limb- and life-threatening condition, which necessitates emergency operation. Prior to therapy, radiological examinations should be performed in order to make accurate diagnoses (21). Color duplex ultrasonography is an easy, non-invasive diagnostic method that can be used to detect pseudoaneurysms and obtain essential information concerning the size and length of the cavity, the presence of a thrombus, the diameter of the neck of a pseudoaneurysm and the possible compression on surrounding tissues (22). However, confusing images may be obtained due to the complex anatomic configuration of this area. Therefore, in the present study, a conclusive and precise CT angiogram was performed for pretreatment evaluation as well as postoperative assessment.

During therapy, hemorrhage-associated complications caused by open surgical repair and invasive traditional treatment may increase the likelihood of mortality (up to $7.5 \%$ within 1 year) (23). Furthermore, surgical treatment for pseudoaneurysm is not recommended in patients with ischemia of surrounding tissues, caused by vascular compromise, nerve compression, deep venous thrombosis, bleeding or infection of the pseudoaneurysm. Although ultrasound-guided compression is highly efficient, it is only applicable for pseudoaneurysms with a narrow neck, which are slow growing, small in size $(<6 \mathrm{~cm}$ in diameter) and located below the inguinal ligament (24). In the present study, all pseudoaneurysms were bleeding and large in size ( $>6 \mathrm{~cm}$ in diameter); therefore, endovascular repair using a covered stent was the primary therapeutic option (25-27). 
Table IV. Follow-up results in patients with pseudoaneurysm in the femoral artery.

\begin{tabular}{|c|c|c|c|c|}
\hline Follow-up result & Postoperation $(\mathrm{n}=29)$ & $\begin{array}{l}\text { Prior to hospital } \\
\text { discharge }(n=29)\end{array}$ & $\begin{array}{c}1 \text { month } \\
\text { follow-up }(n=21)\end{array}$ & $\begin{array}{l}9 \text { months } \\
\text { follow-up }(n=21)\end{array}$ \\
\hline \multicolumn{5}{|l|}{ Pulsatile mass (\%) } \\
\hline Decreased in size & $29(100)$ & $29(100)$ & $18(85.71)$ & $0(0)$ \\
\hline None & $0(0)$ & $0(0)$ & $3(14.29)$ & $21(100)$ \\
\hline \multicolumn{5}{|l|}{ Pain $(\%)$} \\
\hline Without alleviation & $13(44.83)$ & $6(20.69)$ & $0(0)$ & $0(0)$ \\
\hline Alleviation & $16(55.17)$ & $15(51.72)$ & $5(23.81)$ & $0(0)$ \\
\hline Without pain & $0(0)$ & $8(27.59)$ & $16(76.19)$ & $21(100)$ \\
\hline Stent thrombosis (\%) & $1(3.45)$ & $0(0)$ & $0(0)$ & $0(0)$ \\
\hline Patency of distal femoral artery (\%) & $29(100)$ & $29(100)$ & $21(100)$ & $21(100)$ \\
\hline $\mathrm{ABI}$ & $0.52 \pm 0.09$ & $0.92 \pm 0.05^{\mathrm{a}}$ & $0.96 \pm 0.27^{\mathrm{a}}$ & $0.97 \pm 0.37^{\mathrm{a}}$ \\
\hline
\end{tabular}

Values are expressed as the mean \pm standard deviation or $\mathrm{n}(\%)$. ${ }^{\mathrm{a}} \mathrm{P}<0.001$ compared with postoperation $(\mathrm{ABI}=0.52 \pm 0.09)$. ABI, ankle-brachial index.

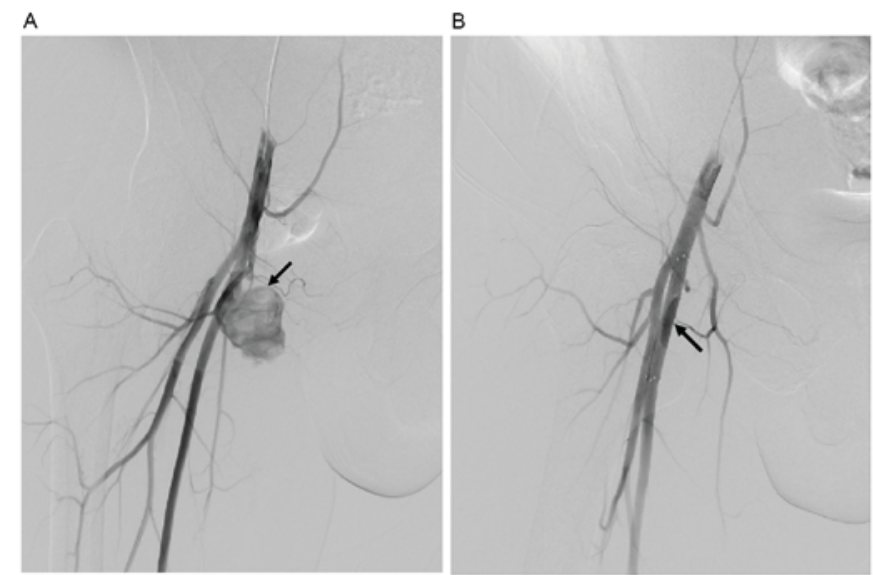

Figure 3. Digital subtraction angiogram findings of one case intraoperation and postoperation. (A) FA arteriogram detected a $62.8 \times 80 \mathrm{~mm}$ pseudoaneurysm (black arrow). (B) Completion aortogram revealed no evidence of endoleak, disappearance of the aberrant SFA pseudoaneurysm lumen and patency of the SFA following 6x80 mm stent deployment. SFA, superficial femoral artery.

Interventional stenting is an alternative to open surgery, which has been reported to demonstrate an improvement over percutaneous transluminal angioplasty alone for the treatment of aortoiliac and femoral occlusive disease since 1969 (28). Compared with angioglasty, stent placement yields similar complication rates; however, the technical success rate of stenting is often higher and the risk of long-term failure may be reduced (29-31). Therefore, stenting is considered an established therapeutic modality for the treatment of iliac artery stenosis and occlusion. Stents can prevent late vessel remodeling by mechanically scaffolding the vessel wall. By testing various types of stents, uncovered stents may secure intimal flaps and seal the dissected vessel wall, and can treat acute or threatened vessel closure following unsuccessful balloon angioplasty. However, long-term results in large lesions may be compromised by restenosis. Despite this, covered stents lined with expanded polytetrafluoroethylene have the potential

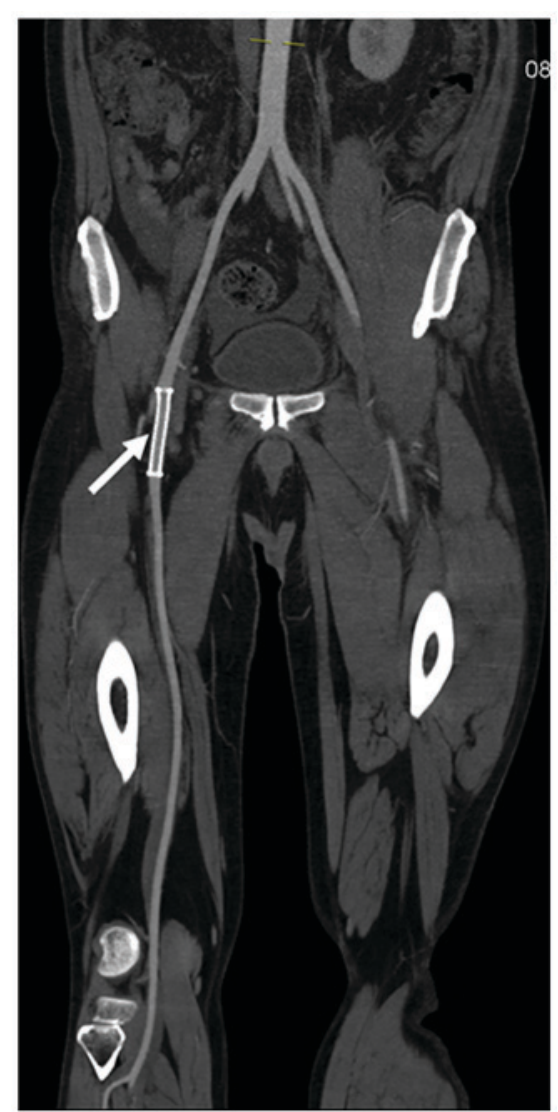

Figure 4. Image of one case during follow-up. Oblique coronal reformatted CT scan obtained 9 months following stent deployment; the scan showed that the stent (white arrow) and distal branch are patent.

to overcome this limitation by providing a barrier against neointimal hyperplasia, thus potentially increasing stent patency (32).

Due to the non-invasive nature of the treatment described in the present study, the mean operation time was $70 \pm 15 \mathrm{~min}$, and the hospitalization time was $2 \pm 1.32$ days due to the lower rate of wound and infection. The durations of the operation 
and hospitalization associated with covered stent placement were significantly shorter compared with those associated with surgical operation $(3 \pm 0.2 \mathrm{~h}$ and $15.9 \pm 14.7$ days, respectively) (33). Furthermore, such a minimally invasive therapeutic approach avoids the physiological burden of surgical repair and its associated risks, particularly in cachectic, immunocompromised patients with poor general health and nutritional status (12). Furthermore, due to lack of associated restenosis and reduced wound rate, ABI values were markedly increased during the follow-up. In a previous study, 9 months postoperation, ABI values were stable, and no significant differences were reported compared with in normal legs (34).

The primary aim of treating ruptured pseudoaneurysms is to reduce the risk of mortality and reserve lower extremity functionality, particularly in young patients who have no atheroma and therefore no collateral vessels (33). According to clinical experience, FA reservation is a prerequisite to blood flow to the lower extremity. Covered stent implantation excludes the aneurysm sac from the circulation while preserving sufficient blood flow to distal organs. Furthermore, the stents were implanted away from the origin of SFA with great caution in case of subsequent ischemia of the lower extremity. Therefore, the length of the covered stent should be relatively short, in order to reduce the influence of hip joint motion and lessen thrombotic formation. However, internal leakage can be caused if the stent is too short. Combining our clinical experience with the findings of previous study (35), the diameter of the stent used in the present study depended on, and was slightly larger than, the diameter of the native artery (10-20\% larger). The length of the stent was longer than the injured artery, and the margins were no more than $1 \mathrm{~cm}$ into the superior and inferior segment of the normal artery (35).

Although endovascular repair of a pseudoaneurysm using a covered stent exhibited promising results, there remain some limitations to the present study. Firstly, the present study is a single-center study, which requires confirmation in larger multicenter studies. Secondly, all patients in the present study were drug abusers with traumatic pseudoaneurysms that were admitted to the emergency department; therefore, preoperation clinical data were incomplete and the type of patients was limited. In addition, due to the low compliance of drug abusers, the follow-up only reached 9 months. Finally, the application of covered stents was limited by the disadvantages of the stent itself and the location of the lesion. For example, the FA originates close to the inguinal ligament and repetitive hip flexion during ambulation may result in stent compression, and consequently lead to poor blood flow of the deep FA. Therefore, during the operation, stents should be delivered in an appropriate place so that the proximal FA entry tear is covered by the middle of the stent as soon as possible. The long-term clinical efficacy and safety of this technique, as well as its applicability in other types of pseudoaneurysm, still require investigation.

In conclusion, although further clinical trials are required, these findings are encouraging, and the results indicated that covered stents may be an effective, safe and minimally invasive option for the treatment of SFA pseudoaneurysms.

\section{Acknowledgements}

The authors of the present study would like to thank Dr Hua He, Dr Wenlong Zhang and Dr Xiaobin Yang (Xijing Hospital, Xi'an, China) for acquisition of image data and thoughtful suggestions.

\section{References}

1. Siani A, Flaishman I, Siani LM, Mounayergi F, Zaccaria A, Schioppa A and Baldassarre E: Spontaneous rupture of the superficial femoral artery treated via an endovascular approach. Tex Heart Inst J 35: 66-68, 2008.

2. Dhillon MS, McCafferty I, Davies AM and Tillman RM: Intra-osseous pseudoaneurysm following curettage of an aneurysmal bone cyst. Skeletal Radiol 36 (Suppl 1): S46-S49, 2007.

3. World Drug Report 2010. United Nations Office on Drugs and Crime (UNODC). United Nations Publication Sales No.E.10. XI.13.

4. Tsao JW, Marder SR, Goldstone J and Bloon AI: Presentation, diagnosis, and management of arterial mycotic pseudoaneurysms in injection drug users. Ann Vasc Surg 16: 652-662, 2002.

5. Karkos CD, Kalogirou TE, Giaqtzidis IT and Papazoglou KO: Ruptured mycotic common femoral artery pseudoaneurysm: Fatal pulmonary embolism after emergency stent-grafting in a drug abuser. Tex Heart Inst J 41: 634-637, 2014.

6. Imsand D and Hayoz D: Current treatment options of femoral pseudoaneurysms. Vasa 36: 91-95, 2007.

7. Kronzon I: Diagnosis and treatment of iatrogenic femoral artery pseudoaneurysm: A review. J Am Soc Echocardiogr 10: 236-245, 1997.

8. Qin J, Huang L, Li AM, Song YM, Jin J, Yu XJ, Zhou XB, Lin CM, Gao YH, et al: Comparison of ultrasound-guided thrombin injection and compression repair in treatment of iatrogenic femoral arterial pseudoaneurysms. J Med Coll PLA 21: 261-267, 2006.

9. Lönn L, Olmarker A, Geterud K and Risberg B: Prospective randomized study comparing ultrasound-guided thrombin injection to compressionin the treatment of femoral pseudoaneurysms. J Endovasc Ther 11: 570-576, 2004.

10. D'Ayala M, Smith R, Zanieski G, Fahoum B and Tortólani AJ: Acute arterial occlusion after ultrasound-guided thrombin injection of a common femoral artery pseudoaneurysm with a wide, short neck. Ann Vasc Surg 22: 473-475, 2008.

11. Ahmad F, Turner SA, Torrie P and Gibson M: Iatrogenic femoral artery pseudoaneurysms: A review of current methods of diagnosis and treatment. Clin Radiol 63: 1310-1316, 2008.

12. Antoniou GA, Papas TT, Tsagkos I, Trachanellis S, Antoniou SA, Tsanis A and Bessias N: Endovascular stent-graft repair of bleeding common femoral artery pseudoaneurysm in intravenous drug users: A bridge to surgical reconstruction. Vasa 43: 473-476, 2014

13. Karkos CD, Kalogirou TE, Giagtzidis IT and Papazoglou KO: Ruptured mycotic common femoral artery pseudoaneurysm: Fatal pulmonary embolism after emergency stent-grafting in a drug abuser. Tex Heart Inst J 41: 634-637, 2014.

14. McGraw JK, Patzik SB, Gale SS, Dodd JT and Boorstein JM: Autogenous vein-covered stent for the endovascular management of a superior mesenteric artery pseudoaneurysm. J Vasc Interv Radiol 9: 779-782, 1998.

15. Ramus JR, Gibson M, Magee T and Torrie P: Spontaneous rupture of the superficial femoral artery treated with endovascular stent grafting. Cardiovasc Intervent Radiol 30: 1016-1019, 2007.

16. Samara O, Saleh AI, Alomari A, AI Ryalat N, Hadidy A and Alsmady M: Giant spontaneous femoral artery pseudoaneurysm treated with covered stents: Report of a rare presentation and review of literature. Sultan Qaboos Univ Med J 13: E472-E475, 2013.

17. Lammer J,Zeller T, Hausegger KA, Schaefer PJ, Gschewendtner M, Muller-Huelsbeck S, Rand T, Funovics M, Wolf F, Rastan A, et al: Heparin-bonded covered stents versus bare-metal stents for complex femoropopliteal artery lesions: The randomized VIASTAR trial (Viabahn endoprosthesis with PROPATEN bioactive surface [VIA] versus bare nitinol stent in the treatment of long lesions in superficial femoral artery occlusion disease). J Am Coll Cardiol 62: 1320-1327, 2013. 
18. Alsmady M, Abdallah F, Shanti H and Samara O: Spontaneous femoral artery pseudoaneurysm in a young patient. J Surg Case Rep 2012: 18, 2012

19. McIlroy MA, Reddy D, Markowitz N and Saravolatz LD: Infected false aneurysms of the femoral artery in intravenous drug addicts. Rev Infect Dis 11: 578-585, 1989.

20. Ting AC and Cheng SW: Femoral pseudoaneurysms in drug addicts. World J Surg 21: 783-787, 1997.

21. Starnes BW and Arthurs ZM: Endovascular management of vascular trauma. Perspect Vasc Surg Endovasc Ther 18: 114-129, 2006.

22. Posner SR, Wilensky J, Dimick J and Henke PK: A true aneurysm of the profundafemoris artery: A case report and review of the English language literature. Ann Vasc Surg 18: 740-746, 2004.

23. Dzijan-Horn M, Langwieser N, Groha P, Bradaric C, Linhardt M, Böttiger C, Byrne RA, Steppich B, Koppara T, Gödel J, et al: Safety and efficacy of a potential treatment algorithm by using manual compression repair and ultrasound-guided thrombin injection for the management of iatrogenic femoral artery pseudoaneurysm in a large patient cohort. Circ Cardiovasc Interv 7 207-215, 2014.

24. Latic A, Delibegovic M, Pudic I, Latic F, Samardzic J and Karmela R: Non-invasive ultrasound guided compression repair of post puncture femoral pseudoaneurysm. Med Arh 65: 113-114, 2011.

25. Riesenman PJ, Farber MA, Rich PB, Sheridan BC, Mendes RR, Marston WA and Keagy BA: Outcomes of surgical and endovascular treatment of acute traumatic thoracic aortic injury. J Vasc Surg 46: 934-940, 2007.

26. Ott MC, Stewart TC, Lawlor DK, Gray DK and Forbes TL: Management of blunt thoracic aortic injuries: Endovascular stents versus open repair. J Trauma 56: 565-570, 2004.

27. Kasarajan K, Heffernan D and Langsfeld M: Acute thoracic aortic trauma: A comparison of endoluminal stent grafts with open repair and nonoperative management. Ann Vasc Surg 17: $589-595,2003$
28. Blum U, Gabelmann A, Redecker M, Nöldge G, Dornberg W, Grosser G, Heiss W and Langer M: Percutaneous recanalization of iliac artery occlusions: Results of a prospective study. Radiology 189: 536-540, 1993.

29. Puech-Leão P, Wolosker N, Zerati AE and Nascimento LD: Impact of endovascular technique in vascular surgery training at a large university hospital in Brazil. J Surg Educ 68: 19-23, 2011

30. Wolosker N, Mendes Cde A, Jacob CE, Woloker AM and Puech Leão P: Endovascular infrarenal aortic aneurysm repair combined with laparoscopic cholecystectomy. Clinics (Sao Paulo) 65: 743-744, 2010.

31. Ferreira J, Canedo A, Brandão D, Maia M, Braga S, Chaparro M, Barreto P and Vaz G: Isolated iliac artery aneurysms: Six-year experience. Interact Cardiovasc Thorac Surg 10: 245-248, 2010.

32. Virmani R, Kolodgie FD, Dake MD, Silver JH, Jones RM, Jenkins $M$ and Gillespie DL: Histopathologic evaluation of an expanded polytetrafluoroethylene-nitinol stent endoprosthesis in canine iliofemoral arteries. J Vasc Interv Radiol 10: 445-456, 1999.

33. Devecioglu M, Settembre N, Samia Z, Elfarra M and Malikov S: Treatment of arterial lesion in drug addicts. Ann Vasc Surg 28: 184-191, 2014.

34. Duda SH, Bosiers M, Pusich B, Hüttl K, Oliva V, Müller-Hülsbeck S, Bray A, Luz O, Remy C, Hak JB and Beregi JP: Endovascular treatment of peripheral artery disease with expanded PTFE-covered nitinol stents: Interim analysis from a prospective controlled study. Cardiovasc Intervent Radiol 25: 413-418, 2002.

35. LiZ,Zhao L, Wang K, Cheng J,Zhao Y and Ren W: Characteristics and treatment of vascular injuries: A review of 387 cases at a Chinese center. Int J Clin Exp Med 7: 4710-4719, 2014.

(c) (i) () $($ This work is licensed under a Creative Commons C. Attribution-NonCommercial-NoDerivatives 4.0 International (CC BY-NC-ND 4.0) License. 